\title{
Effect of Loading Path on the Mechanical Properties of Completely Decomposed Granite Soil Based on the Multiscale Method
}

\author{
Yanru Zhao, ${ }^{1}$ Tiande Wen $\mathbb{D}^{1},{ }^{1}$ Xiaohui Sun $\left(\mathbb{D},{ }^{1}\right.$ Liping Huang, ${ }^{2}$ and Rui Chen ${ }^{3}$ \\ ${ }^{1}$ Civil Engineering Department, Shenzhen University, Shenzhen 518060, China \\ ${ }^{2}$ Shenzhen Talents Housing Group Co., Ltd., Shenzhen 518036, China \\ ${ }^{3}$ Civil Engineering Department, Harbin Institute of Technology, Harbin, Heilongjiang, China
}

Correspondence should be addressed to Tiande Wen; tiandewen8@126.com

Received 16 December 2020; Revised 11 January 2021; Accepted 15 January 2021; Published 30 January 2021

Academic Editor: Meng Jingjing

Copyright ( $\odot 2021$ Yanru Zhao et al. This is an open access article distributed under the Creative Commons Attribution License, which permits unrestricted use, distribution, and reproduction in any medium, provided the original work is properly cited.

Mechanical properties of intact completely decomposed granite (CDG) soil, widely distributed in South China, decrease drastically as encountering external load-related disturbance or soaked by water. In this study, staged triaxial consolidated drained (CD) test and microscopic scanning were conducted using intact CDG specimens extracted from a construction site to investigate the mechanical behavior and microscopic pore distribution. The results show that the stress-strain relationship reveals a shrinking behavior in the first-stage loading and a brittle behavior in the second-stage loading. The development of cracks is affected by the principal stress, which causes the pores and cracks to shrink or partially close. In addition, $E_{s e c-1}$ increases linearly with the increase of confining pressure, but $E_{s e c-2}$ decreases exponentially.

\section{Introduction}

With the rapid economic development of Shenzhen in recent years, a large number of modern infrastructures (metros) have been constructed extensively. Meanwhile, engineering problems, such as failures of cutting slopes and excessive uplifting of tunnels, occur frequently in this area that is mainly covered with completely decomposed granite (CDG) soils. Completely decomposed granite soil is widely distributed in many parts of the world. It approximately covers $40 \%$ of the surface land area with thickness in the range of $0-60 \mathrm{~m}$ in Shenzhen, China [1-3]. The main mineral ingredients of CDG soil are feldspar, mica, and quartz [4]. In general, CDG soil has an inherently heterogeneous nature since the mineralogy of the parent rock undergoes intense variations in the process of chemical weathering, physical disintegration, hydrothermal alteration, and migration [5].

The CDG at the top of the tunnel will induce the floating deformation in a loading-unloading process; therefore, it is necessary to obtain the CDG soil properties for construction guidance [6-16]. Lan et al. [3] statistically analyzed the differences in composition, stress, and strain characteristics of CDG with different degrees of weathering in southern China. Dassekpo et al. [17] studied the compressive strength after the addition of CDG to fly ash to initiate the polymerization reaction and to form a new geopolymer material. Wang et al. [18] investigated the effects of fines contents on the mechanical behavior of CDG during dynamic compaction grouting. The shear strength parameters of the CDG can also be used for the stability calculation of the excavation slope $[19,20]$. Meanwhile, understanding the relationship between secant modulus and unloading modulus and confining pressure is crucial to evaluate the deformation of infrastructures such as filled subgrade settlement or tunnel uplift problem involving the weathered granite profile [21-25].

$\mathrm{X}$-ray microtomography is a noninvasive and nondestructive technique that allows the study of morphological properties of the structure of the soil $[26,27]$. Some scholars have used this technique in recent years to measure the evaluation of several soil structural properties such as porosity, number of pores, pore size, and connectivity [28-33]. Helliwell et al. [34] observed significant changes in the soil structure in repacked cores after a single wetting and drying 
event, though further W-D had little impact. Feng et al. [35] proposed a standard section to quantify the basic distribution characteristics of soil pores by CT scanning of 45 cylindrical soil columns. Martínez et al. $[36,37]$ used fractal dimensions to describe large-pore spatial structures based on CT scan results. However, there has been less experimental research on the influence of stress path on microscopic porosity of CDG.

In this study, intact CDG specimens were prepared for the triaxial consolidated drained (CD) test and microscopic scanning experiment to investigate the effects of consolidated drained and initial structural damage on the mechanical behavior such as stress-strain characteristics, shear strength, deformation properties, and microscopic pore distribution.

\section{Materials and Methods}

2.1. Specimen Preparation. The intact granite residual soil samples were extracted at a site with a natural granite residual soil layer located in Shenzhen, China $(X=111936.850$, $Y=27410.640$, and $Z=72.68$ ), and the specimens were extracted at depths of 19.8-23.4 $\mathrm{m}$ using a bucket auger from a foundation pit excavation. In total, a series of specimens with a dimension of $125 \mathrm{~mm}$ in height and $60 \mathrm{~mm}$ in diameter were taken from the site and prepared for testing. Basic indices of the specimens are summarized in Table 1. According to the Unified Soil Classification System (USCS), the typical CDG soil is classified as SC or CL. The CDG specimens in this study are classified as SC, with an average moisture content of $26.15 \%$, an average void ratio of 0.923 , and an average density of $1.84 \mathrm{~g} / \mathrm{cm}^{3}$. Complete grain size distribution curve from gravel size to clay size of CDG soil was captured using wet sieving and hydrometer tests following the standard BS1377-2 [39]. The typical upper and lower bounds for the percentage of silt particles were determined as $78 \%$ and $23 \%$, respectively (see Figure 1).

2.2. Triaxial Test Procedure. The stress-controlled triaxial test under CD condition was performed using a GDS-stress path apparatus (see Figure 2). All the prepared specimens were first percolated with carbon dioxide and then saturated with water. Triaxial tests under CD condition were carried out in accordance with the standard ASTM D7181-11 [40]. Prior to the shearing test, three steps were performed as follows.

Firstly, a vacuum of $50 \mathrm{kPa}$ was used to evacuate air bubbles, followed by flushing the specimen with carbon dioxide for at least $1 \mathrm{~h}$. Back pressure of $25 \mathrm{kPa}$ was required to achieve the value of pore pressure coefficient ( $B$ value) exceeding 0.97 .

Secondly, the soil specimens were isotropically consolidated under a prescribed confining pressure of $50-240 \mathrm{kPa}$. The confining pressure was applied to the specimens at a rate of $0.1 \mathrm{MPa} / \mathrm{s}$ and reached a preset value according to the calculated confining pressure of the specimen at different depths.
After that, the specimen was sheared at a controlled rate of $0.0009 \mathrm{~mm} / \mathrm{min}$ [10]. During the shearing test, pore water was allowed to drain out slowly to ensure fully drained conditions. One loading (0 cyclic loading) triaxial test was performed by increasing the applied deviator stress from 0 to $\left(\sigma_{1}-\sigma_{3}\right)_{f}$ (see path I shown in Figure 3 ) with different confining pressures $(100,200,300$, and $400 \mathrm{kPa})$. As for the second-stage loading (1 cyclic loading) test, it was performed by applied loading to a preset value (classified as $T-1 \#=100$, $T-2 \#=200, T-3 \#=300$, and $T-4 \#=400 \mathrm{kPa}$, see paths II-IV in Figure 3) and then unloading to zero. After that, reloading process was conducted, and the deviator stress increased from 0 to $\left(\sigma_{1}-\sigma_{3}\right)_{f}$ as failure of the specimen was observed or the accumulation of axial strain reached the axial strain of $13 \%$.

2.3. CT Scanning and Image Acquisition. Under the strain rate $(0.0009 \mathrm{~mm} / \mathrm{min})$, the pore structure will evolve slowly without drastic change that may cause the sudden collapse of the soil column. Obviously, the column would deteriorate along the loading process. To capture the change of the microstructure, X-ray CT scanning was performed by a GEN $\mathrm{X}$-ray CT scanner (model: discovery $750 \mathrm{CT}$ ) located in the Hospital of University of Peking, China. The CT scanner produces images based on the attenuation of X-rays penetrating into different types of matters. During scanning, the soil columns after shear failure were placed horizontally on the scanning platform so that the X-ray beam could be perpendicular to the longitudinal axis of the soil column. Figure 4 illustrates the steps of the image processing method in this study.

\section{Results and Discussion}

3.1. Stress-Strain Properties. Figure 5 shows the relationship of stress-strain and volumetric strain corresponding to the first-stage loading condition for the CDG specimens. Figure 5(a) shows that strain softening behavior was observed in the lower confining pressure state (100 to $200 \mathrm{kPa})$. On the contrary, strain hardening behavior was observed as confining pressure ranged from 300 to $400 \mathrm{kPa}$. The volumetric strain-axial strain relationship shows a shrinking behavior as confining pressure increased from 100 to $400 \mathrm{kPa}$ (corresponding to loading path I in Figure 3). However, the shrinkage behavior changes to dilative behavior for the stress-strain curves as axial strain exceeds $5.4 \%$ in a low confining pressure of 100 to $200 \mathrm{kPa}$.

The decrease of volumetric strain in the first-stage loading may be attributed to the decrease of the soil void ratio due to the application of external loading pressure. However, as the shearing test under a lower confining pressure continued, a larger lateral deformation was observed due to the loss of binding force of the soil. On the contrary, a continuing shrinking behavior was observed in the test, and it may be contributed to the effect of high confining pressure, which constrained the lateral deformation of the specimen. Despite certain scattering of the data points, they lie close to a unique linear strength 
TABLE 1: Index properties of the CDG soil.

\begin{tabular}{|c|c|c|c|c|c|c|c|c|c|c|c|c|}
\hline \multirow[t]{2}{*}{ Specimen ID } & \multirow[t]{2}{*}{ Depth (m) } & \multicolumn{3}{|c|}{$\begin{array}{c}\text { Grain size } \\
\text { distribution (\%) }\end{array}$} & \multirow[t]{2}{*}{$G_{s}$} & \multirow{2}{*}{$\begin{array}{c}\rho \\
\left(\mathrm{g} / \mathrm{cm}^{3}\right)\end{array}$} & \multirow[t]{2}{*}{$w(\%)$} & \multirow[t]{2}{*}{$e$} & \multirow[t]{2}{*}{ Liquid limit (\%) } & \multirow[t]{2}{*}{ Plastic limit (\%) } & \multirow[t]{2}{*}{ Plasticity index } & \multirow[t]{2}{*}{ USCS [38] } \\
\hline & & Sand & Silt & Clay & & & & & & & & \\
\hline 1 & 19.8 & 35 & 22.5 & 22 & 2.69 & 1.87 & 22.6 & 0.85 & 37.2 & 24 & 13.2 & \\
\hline 2 & 20.4 & 37.4 & 22.8 & 19.8 & 2.71 & 1.81 & 21 & 0.73 & 35.8 & 23 & 12.8 & \\
\hline 3 & 21.0 & 34.4 & 21.5 & 25.1 & 2.69 & 1.86 & 23.8 & 0.89 & 43 & 25.6 & 17.4 & \\
\hline 4 & 21.6 & 31.1 & 22.7 & 27.7 & 2.69 & 1.83 & 24.2 & 0.93 & 44.4 & 26.9 & 17.5 & SC \\
\hline 5 & 22.2 & 18.9 & 18.7 & 39.4 & 2.70 & 1.82 & 32.0 & 1.06 & 46.1 & 28.7 & 17.4 & \\
\hline 6 & 22.8 & 24.9 & 20.7 & 35.8 & 2.72 & 1.81 & 30.1 & 1.00 & 44.3 & 27.4 & 16.9 & \\
\hline 7 & 23.4 & 29.2 & 21 & 31.8 & 2.70 & 1.91 & 25.8 & 0.93 & 41.6 & 27.8 & 13.8 & \\
\hline
\end{tabular}
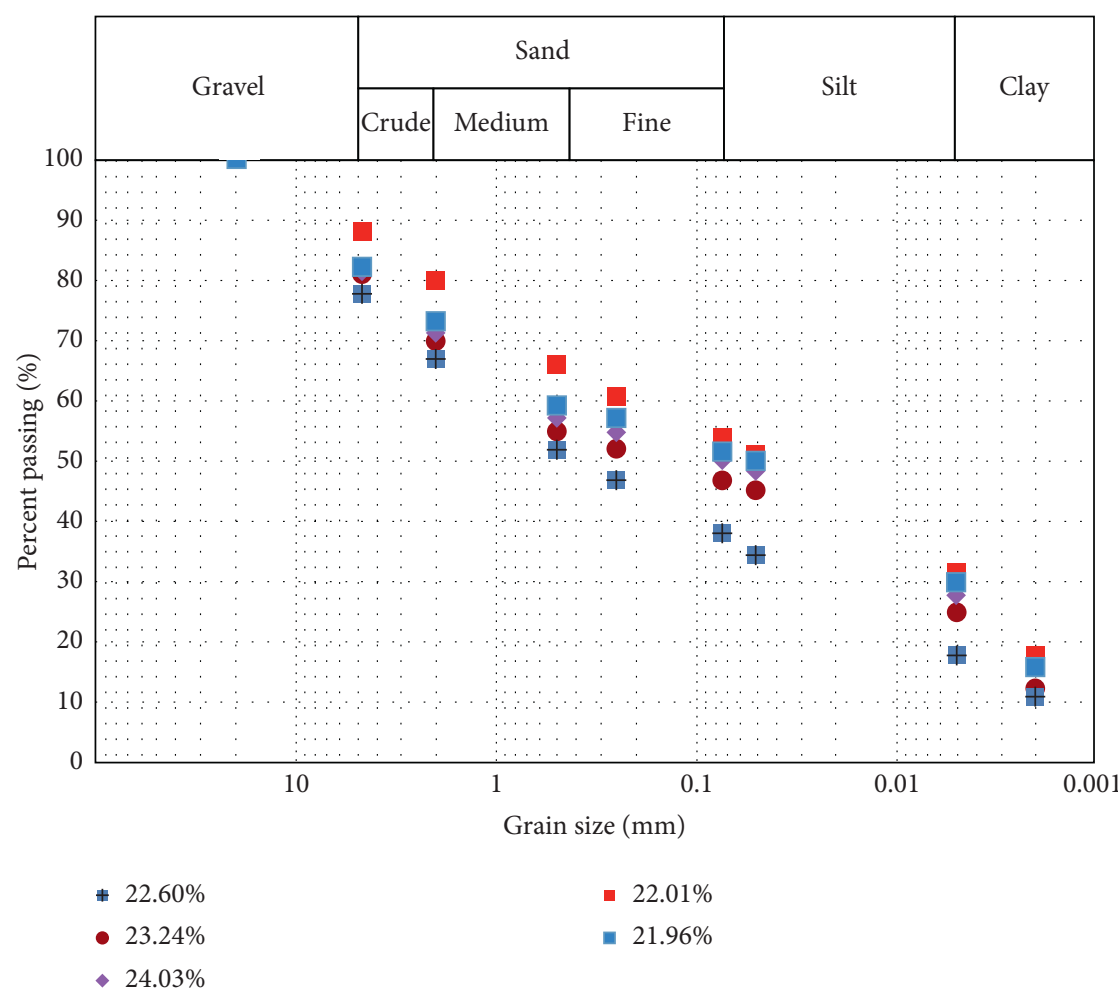

FIgURE 1: Grain size distribution curve of weathered CDG collected at different soil depths.

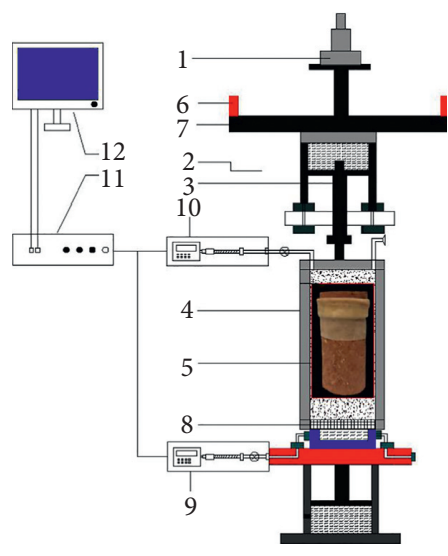

1 Mounting bolts 2 Loading support 3 Bar

4 Test cavity

5 Specimen 6 Displacemrent gauge 7 Metal holder 8 Drainage 9 Back pressure controller 10 Volume controller 11 Signal collection 12 Computer system
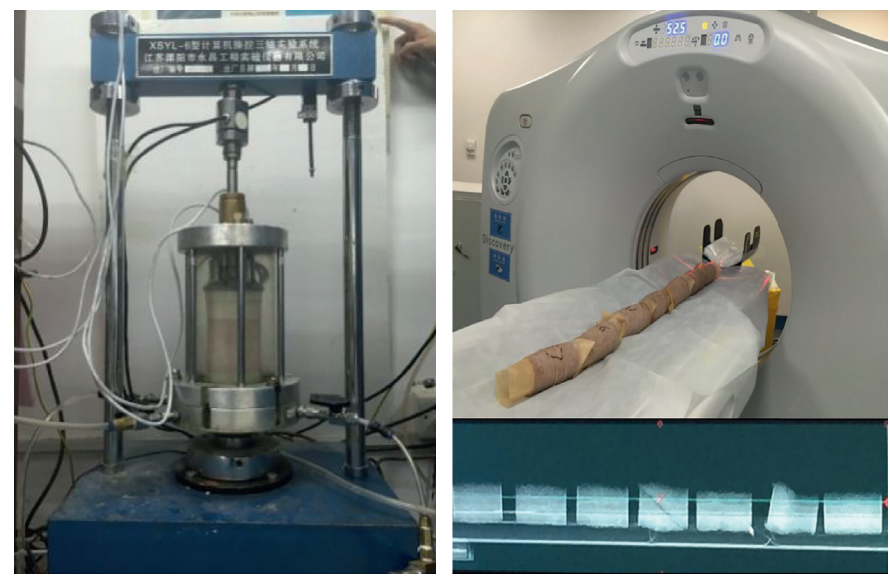

FIgURE 2: Laboratory apparatus used in the triaxial tests and microscopic scanning experiment. 


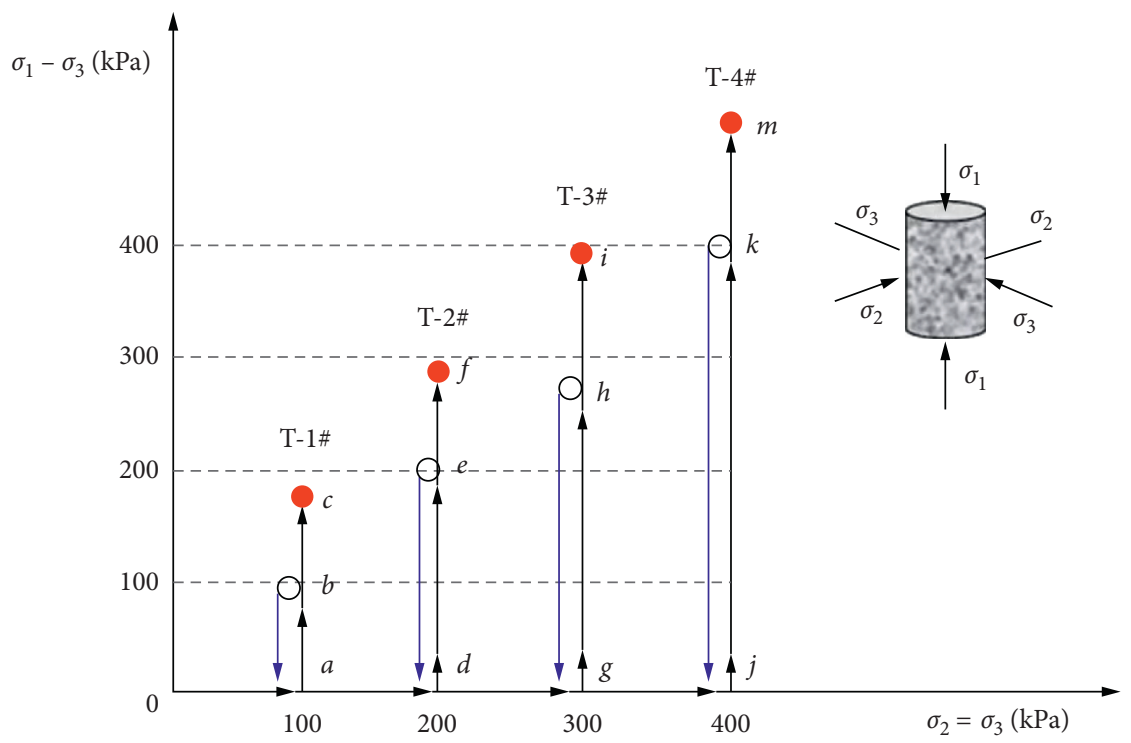

One loading: Path I : loading behavior: $0 \rightarrow a \rightarrow c ; 0 \rightarrow d \rightarrow f ; 0 \rightarrow g \rightarrow i ; 0 \rightarrow j \rightarrow m$;

$$
\begin{aligned}
\begin{array}{c}
\text { Multistage } \\
\text { loading }
\end{array} & \left\{\begin{array}{l}
\text { Path II : loading behavior: } 0 \rightarrow a \rightarrow b ; 0 \rightarrow d \rightarrow e ; 0 \rightarrow g \rightarrow h ; 0 \rightarrow j \rightarrow k ; \\
\text { Path III : unloading behavior: } b \rightarrow a ; e \rightarrow d ; h \rightarrow g ; k \rightarrow j ; \\
\text { Path IV : reloading behavior: } a \rightarrow c ; d \rightarrow f ; g \rightarrow i ; j \rightarrow m ;
\end{array}\right. \\
& \text { Unloading point } \\
& \text { Peak strength point }
\end{aligned}
$$

FIGURE 3: Schematic diagram of the stress paths applied in this study.

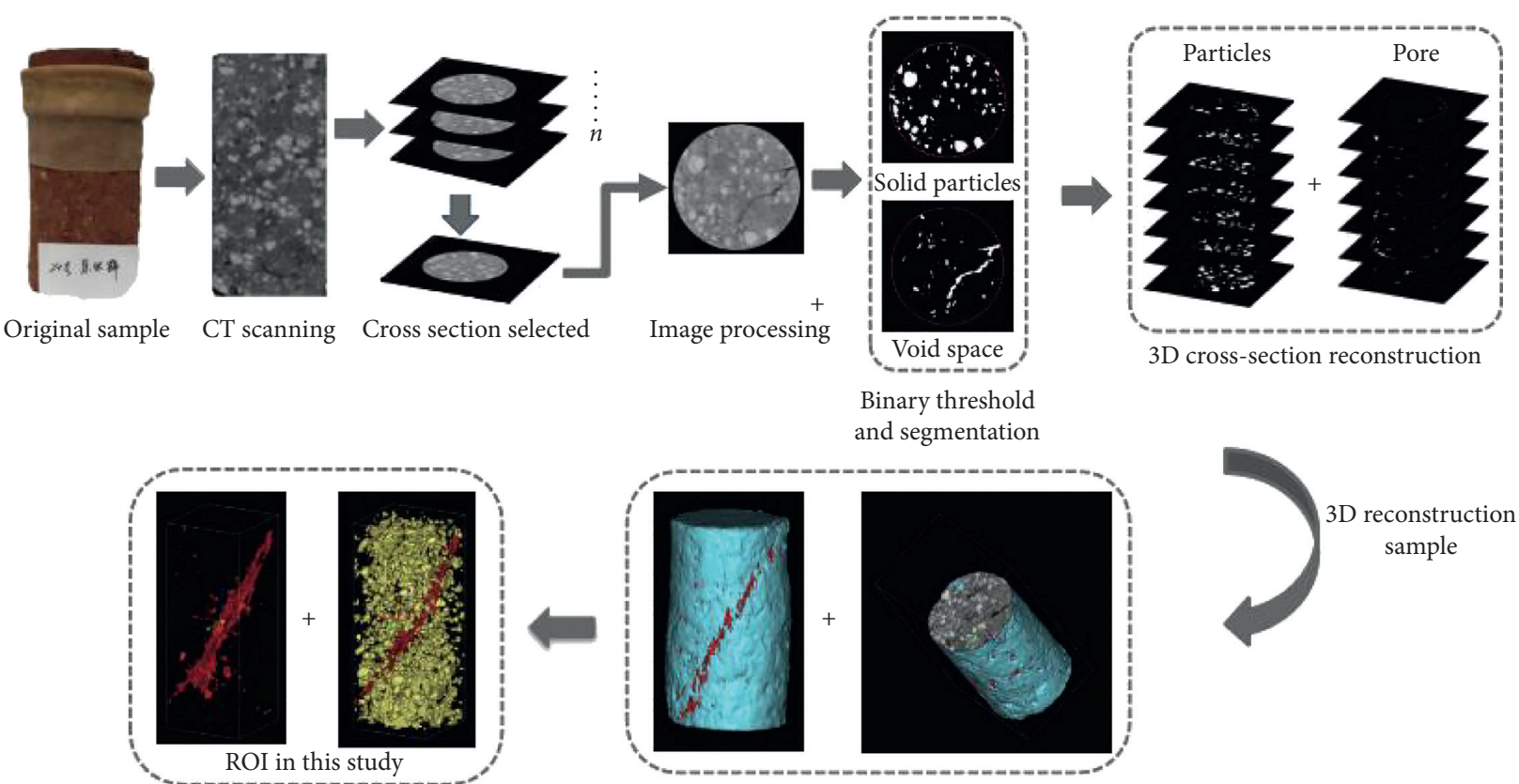

FIGURE 4: Illustration of image processing of this study.

envelope, and the obtained internal friction angle and cohesion were $12^{\circ}$ and $36.7 \mathrm{kPa}$, respectively.

Figure 6 shows the deviator stress $\left(\sigma_{1}-\sigma_{3}\right)$ versus axial strain $(\varepsilon)$ curves associated with the two-stage loading triaxial tests under CD condition with the effective confining pressure of 100, 200,300, and $400 \mathrm{kPa}$. A nonlinear trend of the stress-strain curve was observed, and it becomes more strain hardening as the confining pressure increases in the reloading stage (see path IV as shown in Figure 3 ). In addition, the stress-strain curve demonstrated a brittle soil 


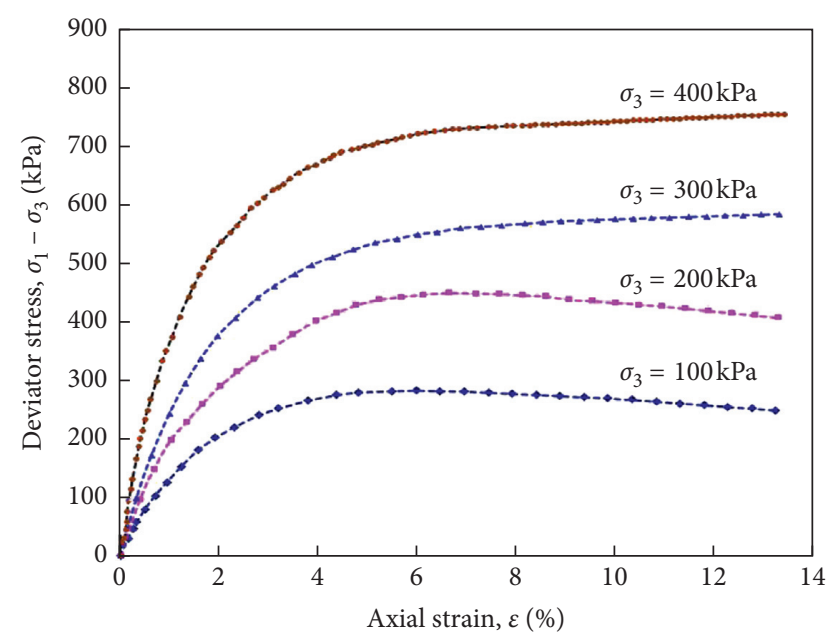

(a)

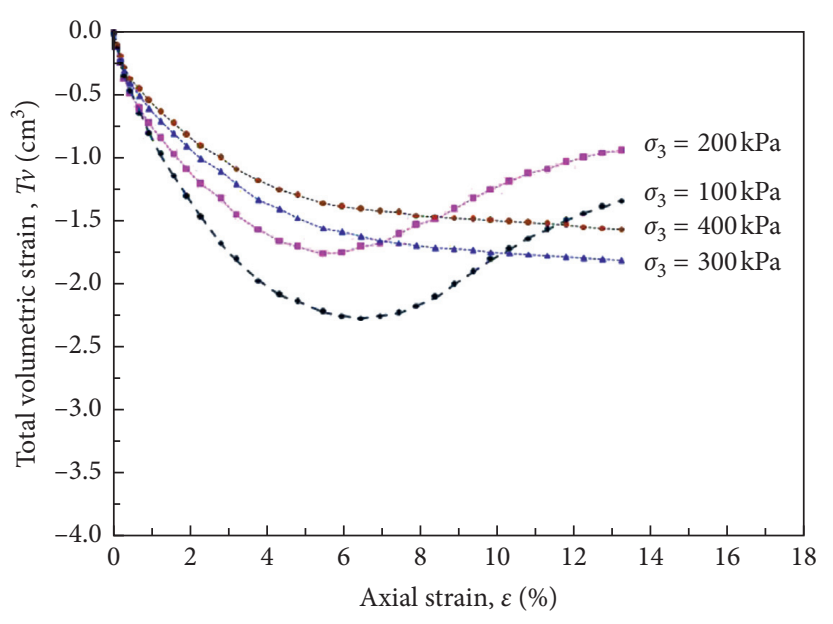

(b)

FIGURE 5: Stress-strain-volume change curves of the CDG soil: (a) deviator stress versus axial strain; (b) total volumetric strain versus axial strain.

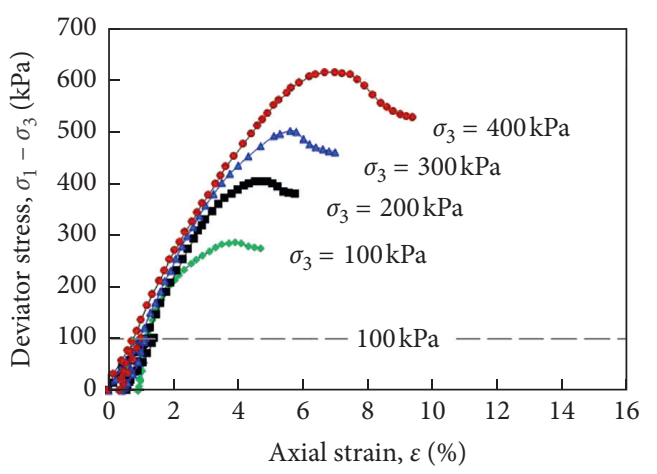

(a)

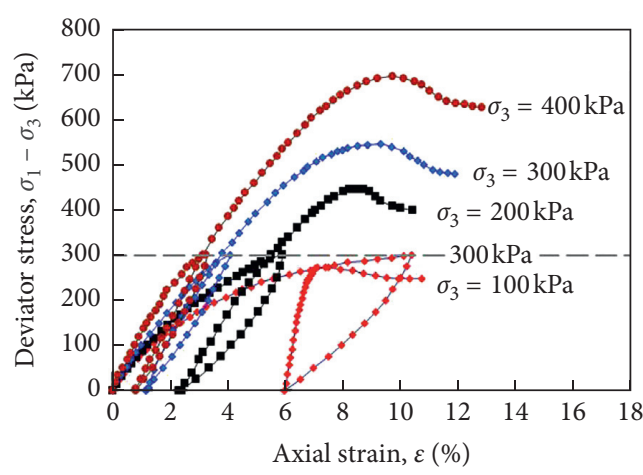

(c)

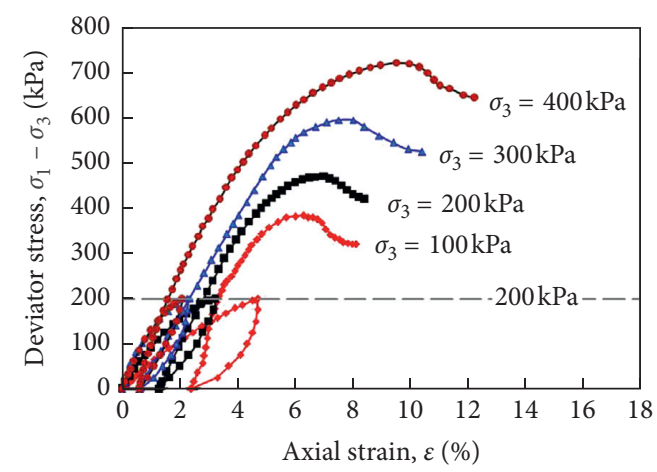

(b)

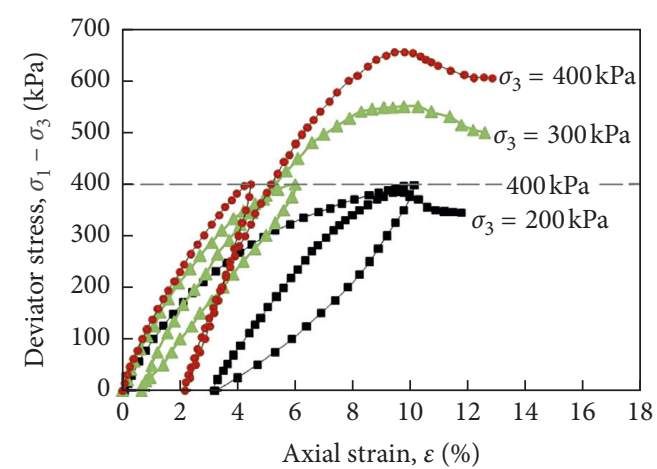

(d)

FIGURE 6: Stress-strain curves of CDG soil at different confining pressures. (a) $\sigma_{1}-\sigma_{3}=100 \mathrm{kPa}$. (b) $\sigma_{1}-\sigma_{3}=200 \mathrm{kPa}$. (c) $\sigma_{1}-\sigma_{3}=300 \mathrm{kPa}$. (d) $\sigma_{1}-\sigma_{3}=400 \mathrm{kPa}$.

behavior during loading path II to path IV, and deviator stress sharply dropped after it apparently reached its equilibrium state. The higher the confining pressure applied, the more obvious the brittle failure characteristic of the CDG soil in the test.

Figure 7 shows that the peak shear strength in the twoloading stage represents a linear regression with the applied deviator stress ranged from 100 to $400 \mathrm{kPa}$. As the confining pressure was $100 \mathrm{kPa}$, the peak shear strength increased from 282 to $384 \mathrm{kPa}$ as the peak strain of the specimen increased from 3.5 to $8.54 \%$. The confining pressure had a significant influence on the peak shear strength after the soil structure was serious damaged due to the larger deviator stress applied. The constant value of confining pressure was $400 \mathrm{kPa}$, 


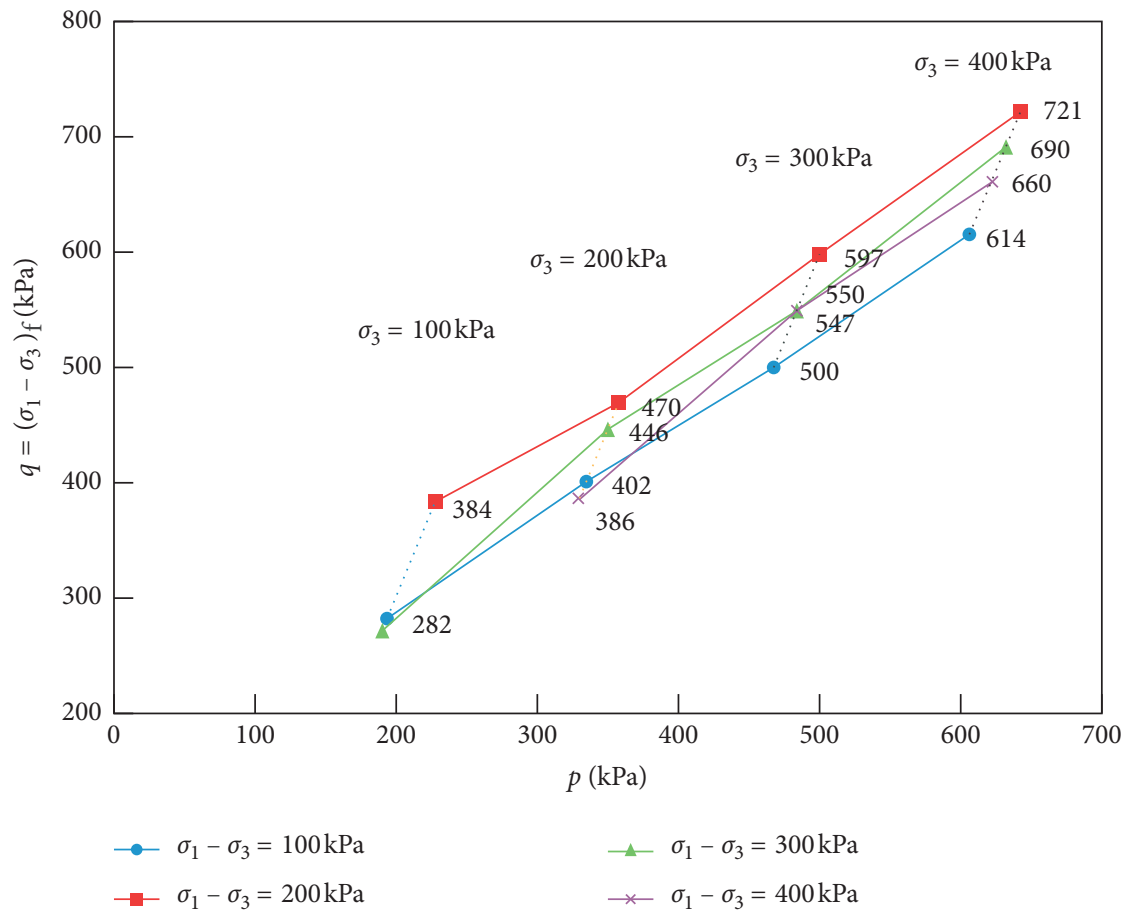

Figure 7: Peak shear strength versus mean stress.

and the peak shear strength firstly increased from 614 to $721 \mathrm{kPa}$ and then decreased to $660 \mathrm{kPa}$ as peak strain ranged from 6.55 to $11.60 \%$.

The stress-strain curves represented a brittle behavior, and deviator stress sharply dropped after it apparently reached its equilibrium state as shown in Figure 6. It indicated that the applied deviator stress may play a preconsolidation role. The determined value of preconsolidation pressure of the specimen was $199.27 \mathrm{kPa}$ in this test. The value of soil preconsolidation pressure was a better index for judging whether the applied external loading is positive or negative for the soil structure strength. Although the peak shear strength was mainly dependent on the self-structure strength, confining pressure had a remarkable effect on the peak shear strength.

3.2. 3D Shear Zone and Shear Strength Parameters. The soil shear strength parameters $c^{\prime}$ and $\varphi^{\prime}$ were obtained using the graphical method based on the Mohr-Coulomb failure theory [41]. Five CDG soil final states are presented in Figure 8 under the consolidated drained and initial structural damage after two-stage loading test according to Figure 6(a).

As shown in Figure 8, the pores in the undisturbed specimen are unevenly distributed along the length of the specimen, and the soil particles in the specimen are also randomly distributed. When the test confining pressure is $100 \mathrm{kPa}, \mathrm{CT}$ scan specimens show that there are inconspicuous clusters and discontinuous fine cracks in the coarse and fine particle cementation sites, and the primary dissolution pores are randomly distributed in the clay minerals. As the external load increases, along the principal stress, the skeleton formed by the coarse particles is affected by the shear stress, causing the coarse particle skeleton to be displaced or deflected and rolled, forming new cracks on the shear plane, and generating the original pores. The tearing effect is partially interpenetrated, showing a nonuniform distribution of local lumps, and no shear failure zone occurs in the soil. Since the axial deformation corresponding to the end of the test was 3.5\%, a nonpenetrated crack was observed, and the dip angle was $26.8^{\circ}$ (marked B). It can be concluded that the stress drop was obviously caused by the localized failure characteristics of the internal pore structure, implying a brittle failure characteristic.

When the confining pressure is $200 \mathrm{kPa}$, the crack at the top of the specimen is developed at a distance of $40 \mathrm{~mm}$ from the corner line. The fragile surface developed along the original hole is gradually expanded and penetrated, and it is not developed in the principal stress axis. The formation of pores in the soil mainly consists of the development of primary pores in the nonpenetrating shear plane and local penetration, and the weaker part of the coarse-fine particles should be cemented and destroyed. The new fissure is predominant with a tear-like shape and partial penetration. The CT pore scanning results show that the cracks corresponding to the shear failure of the specimen spread in the range of $0-40 \mathrm{~mm}$ at the top of the specimen, while the small cracks or the original pores are still randomly distributed in the range of $40-119 \mathrm{~mm}$, and there is no penetration phenomenon. When the soil sample failed, a relatively obvious tear-like shear band is formed, and the axial deformation is $4.73 \%$, with the dip angle of $21.6^{\circ}$.

A nearly $45^{\circ}$ shear zone is formed along the direction of the principal stress when the confining pressure is $300 \mathrm{kPa}$, 

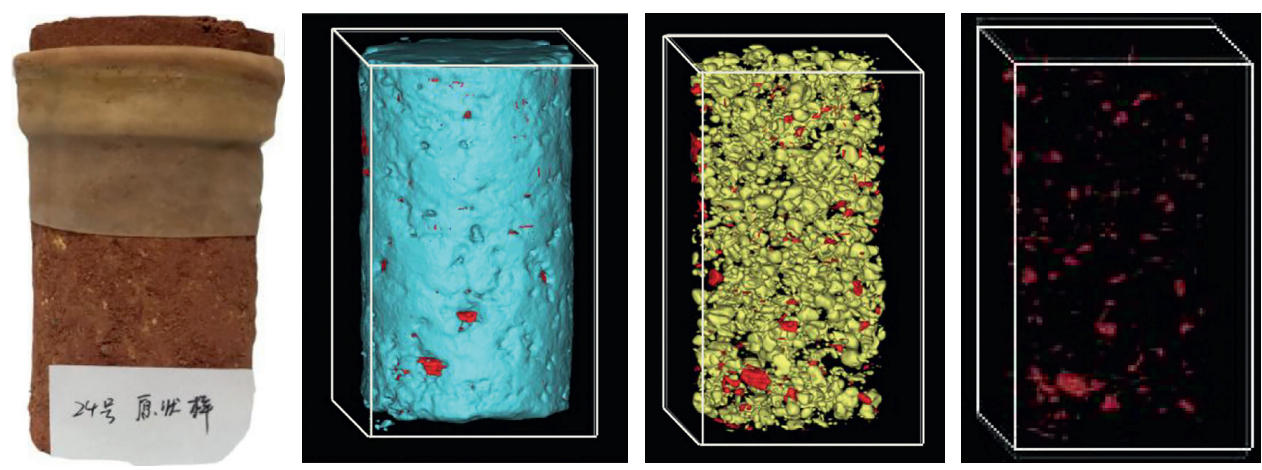

Fine particles + clay minerals $($ dia $<0.18 \mathrm{~mm})$

Fine particles (dia $>0.18 \mathrm{~mm}$ )

Crack + water

(a)
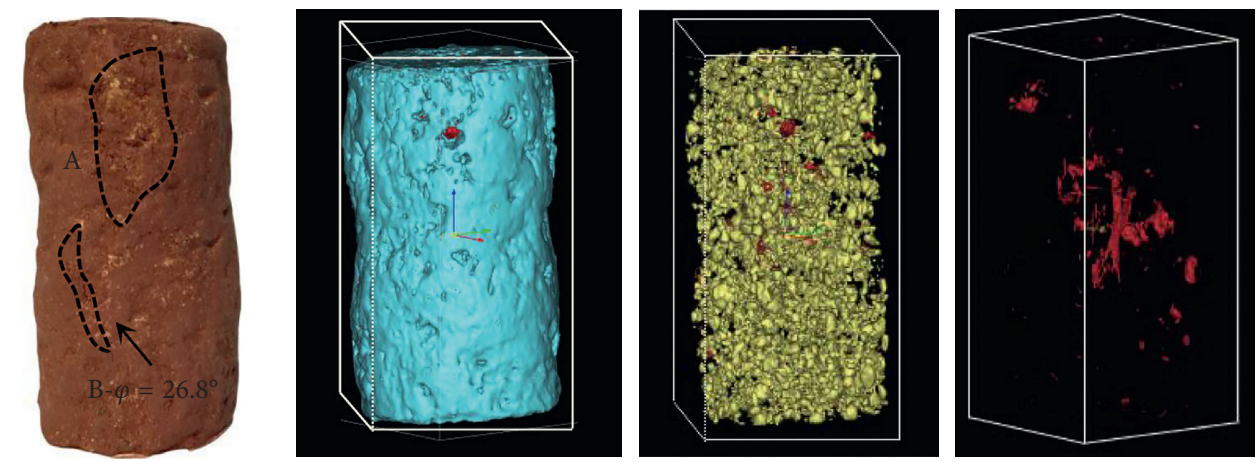

Fine particles + clay minerals $(\mathrm{dia}<0.18 \mathrm{~mm})$

Fine particles (dia $>0.18 \mathrm{~mm}$ )

Crack + water

(b)
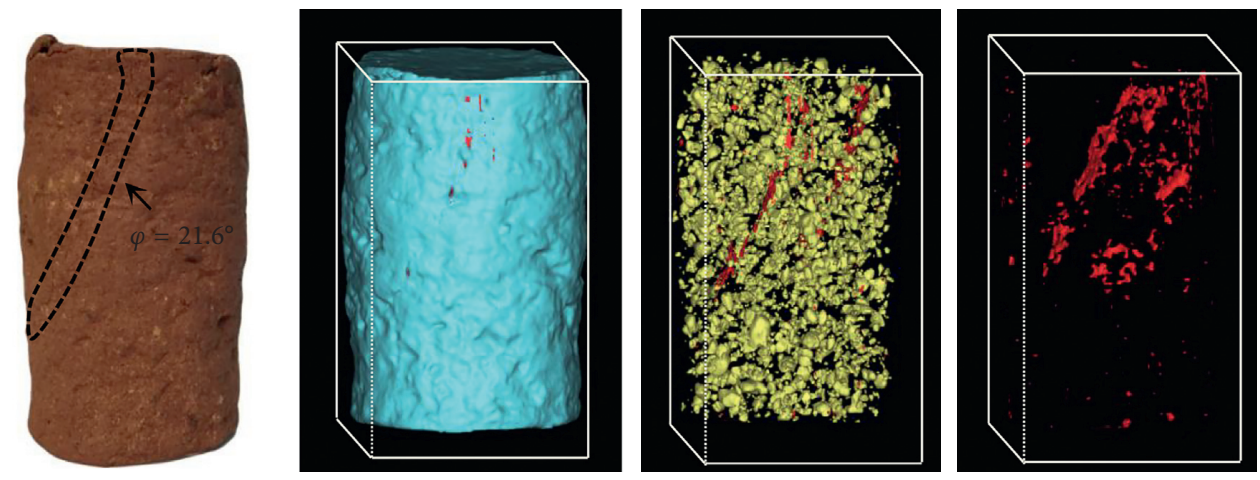

Fine particles + clay minerals $(\mathrm{dia}<0.18 \mathrm{~mm})$

Fine particles (dia $>0.18 \mathrm{~mm})$

Crack + water

(c)

Figure 8: Continued. 

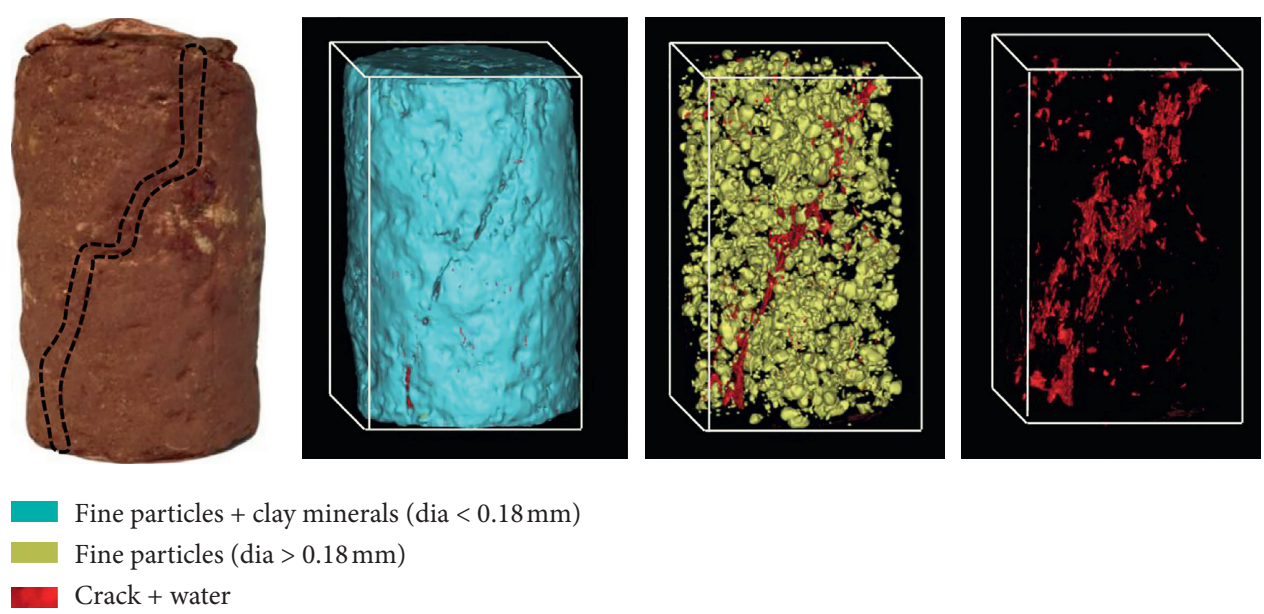

(d)
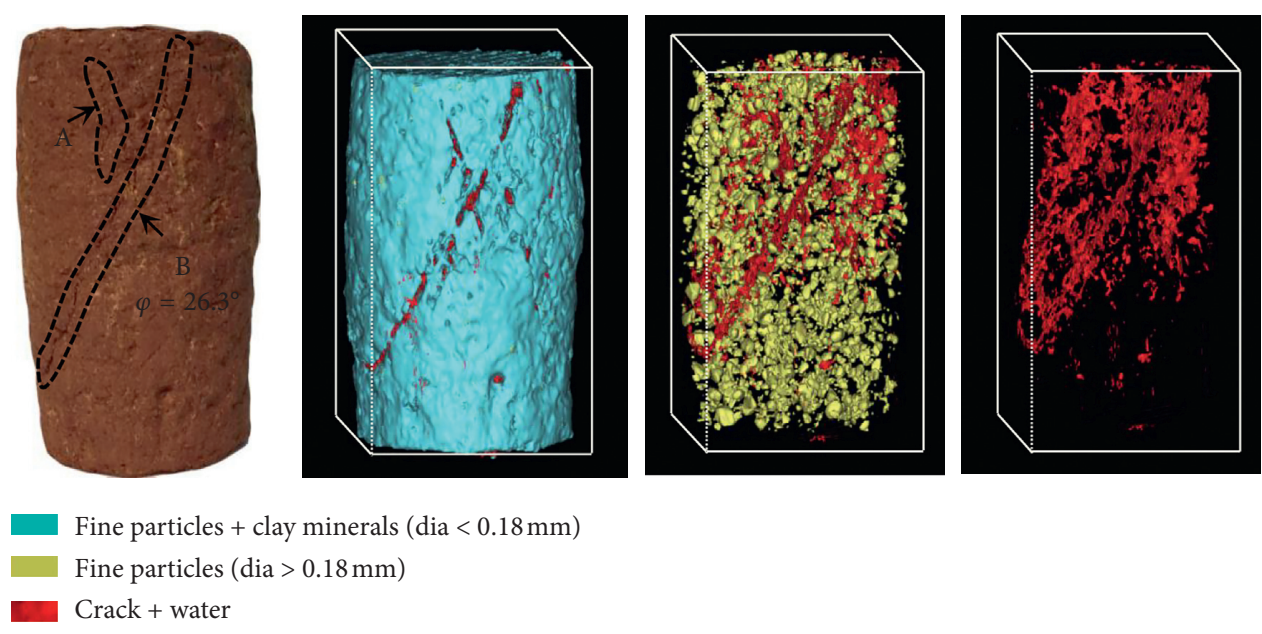

(e)

FIGURE 8: Schematic diagram of crack propagation after a two-stage loading process. (a) Intact soil column $\varepsilon=0 \%$. (b) $\sigma_{3}=100 \mathrm{kPa} \varepsilon=3.50 \%$. (c) $\sigma_{3}=200 \mathrm{kPa} \varepsilon=4.73 \%$. (d) $\sigma_{3}=300 \mathrm{kPa} \varepsilon=5.60 \%$. (e) $\sigma_{3}=400 \mathrm{kPa} \varepsilon=6.67 \%$.

and a large number of nonpenetrating tear-like fracture groups appear in the joints of the coarse-fine particles in the two sides. It was found that the apparent crack propagation of the specimen is consistent with the direction and shape of the internal crack expansion, and the axial deformation at the time of shear failure is $5.60 \%$. When the confining pressure is $400 \mathrm{kPa}$, along the direction of the maximum principal stress of the specimen, the crack of the specimen expands into a complete shear failure zone of $45^{\circ}$, and the thickness of the failure zone is $0.99-2.48 \mathrm{~mm}$. The shear zone consisting of holes is partially convex. This is caused by the inversion of the coarse particles during the shearing process, the displacement, and the tearing of the local coarse-fine particle-cemented soil. In addition, the tiny voids and crack voids randomly distributed in the specimen will gradually disappear under external load and high confining pressure. The axial deformation corresponding to the shear failure of the specimen increases, which is $6.67 \%$. The vertical axial strain of the tested specimen increased as confining pressure increased. It can be concluded that high peak strength was obtained in a high confining pressure state, and the deviatoric stress applied first was a benefit to the improvement of soil stiffness.

The confining pressure has a direct influence on the failure mode of the soil, and the damage of the specimen under low confining pressure has obvious localized failure characteristics, and the failure surface is mainly cracked by the randomly generated weak joint portion. The increase and the development of the crack are controlled by the confining pressure and the principal stress. At the same time, the original pores and cracks of the original principal stress direction are compacted or even partially disappeared. The cracks in the test mainly have the following three types of morphological characteristics: the original pores and cracks in the fine particles of less than $0.18 \mathrm{~mm}$; the cracks are formed and expanded in the weak joints of the coarse particles and fine particles; the coarse particles roll along the principal stress axis due to shear failure, and the soil is reversed and teared to form a new one.

Figure 9 shows that an increase in the shear strength was observed as deviator stress ranged from 0 to $200 \mathrm{kPa}$, and $c^{\prime}$ increased from 36.83 to $51.80 \mathrm{kPa}$, and $\varphi^{\prime}$ increased from 12 

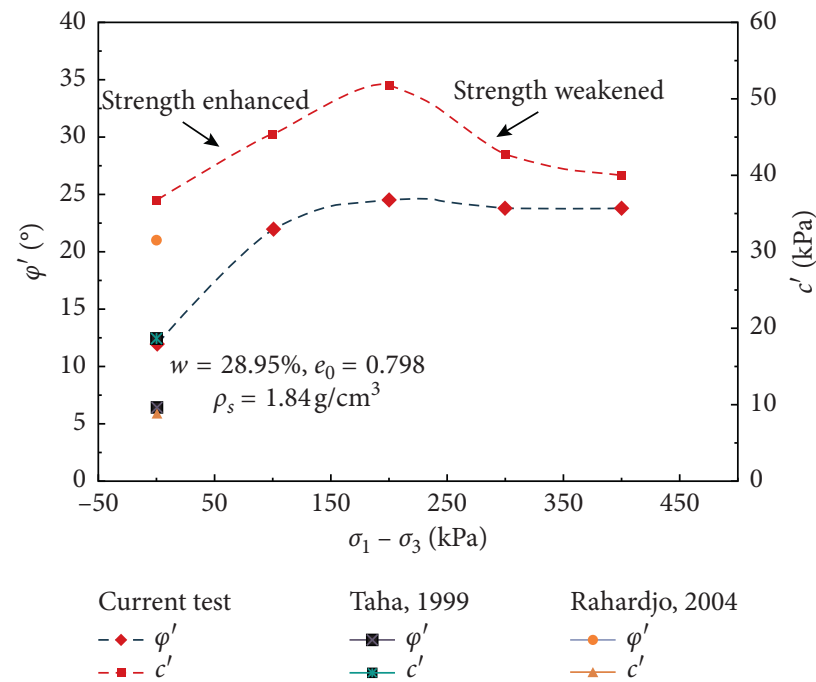

Figure 9: Shear strength vs. deviator stress in the two kinds of triaxial tests.

to $24.5^{\circ}$, respectively. The increase of shear strength can be attributed to the promotion of stiffness with little structural damage due to the low deviator stress applied in the path II stage. However, a reduction for the cohesion was observed after applied deviator exceeds $200 \mathrm{kPa}\left(c^{\prime}\right.$ decreased from 51.8 to $40.1 \mathrm{kPa}$ ), and the friction angle fluctuated in a small range ( $\varphi^{\prime}$ ranged from 24.5 to $\left.23.8^{\circ}\right)$. The test results indicated that the soil structure would be largely damaged by overloading due to the binding breakage of the soil in the first stage. With more microcracks mutually interconnected, a shear crack was formed, and the soil structure was eventually destroyed as the crack gradually run through the specimen section. These test results indicated that the shear strength was mainly self-structure dependent, and high confining pressure had a remarkable influence on the shear strength as its structure was gradually damaged.

3.3. Secant Modulus. Figure 10(a)) shows the relationship between secant modulus $E_{s e c-1}$ and confining pressure $\sigma_{3}$ with respect to different deviator stresses of 100, 200, 300, and $400 \mathrm{kPa}$ in loading path II. The difference for the secant modulus was becoming smaller as the confining pressure increased from 100 to $400 \mathrm{kPa}$. Compared to the current test results, the value of the secant modulus of HK CDG is corresponding to a narrow range of the confining pressure, and the similar linear relationship between $E_{s e c-1}$ and $\sigma_{3}$ was observed [1]. The effect of increased deviator stress on the soil structure damaged was obvious, but the high confining pressure would weaken the degree of damage by means of constraining the lateral deformation of specimens.
Compared to the secant modulus obtained in path II, a declined trend for secant modulus $E_{s e c-2}$ was observed in the path IV stage, and it decreased from 55.10 to $9.70 \mathrm{MPa}$ ( 3 to 5 times larger than $\left.E_{\text {sec-1 }}\right)$ as confining pressure increased from 100 to $400 \mathrm{kPa}$ (due to the serious soil structure damage induced by overloading in path II, the deviator stress failed to reloading to its original fixed deviator stress of 300 and $400 \mathrm{kPa}$ in path IV). The decrease for the secant modulus can be attributed to the soil structure damage in the first loading stage. Meanwhile, the downward trend for the secant has slowed due to the increase of confining pressure. It indicated that the confining pressure has a significant influence on the secant modulus through constraining the lateral deformation of the specimens.

3.4. Unloading Modulus. As a key calculation parameter for evaluating the rebound deformation of the CDG profile, the value of unloading modulus $E_{u r}$ was obtained in the twostage loading test, and the correlation between confining pressure and $E_{u r}$ was also studied.

Figure 11 shows that the unloading modulus $E_{u r}$ increases steadily (62.10 to $158.30 \mathrm{MPa})$ with confining pressure (100 to $400 \mathrm{kPa}$ ), and the correlation between deviator stress and unloading modulus agrees well with the linear function (fitting parameter of $K_{u r}: 103.944,98.424$, 89.330 , and 77.589 and $n: 0.182,0.224,0.343$, and 0.585 with respect to different deviator stresses of 100 to $400 \mathrm{kPa}$ ). It is obvious that the rate of increase of unloading modulus is greater in lower preset deviator stress (i.e., $k$ represented the slope of fitting curves, and it increased from 0.123 to 0.190 ). 


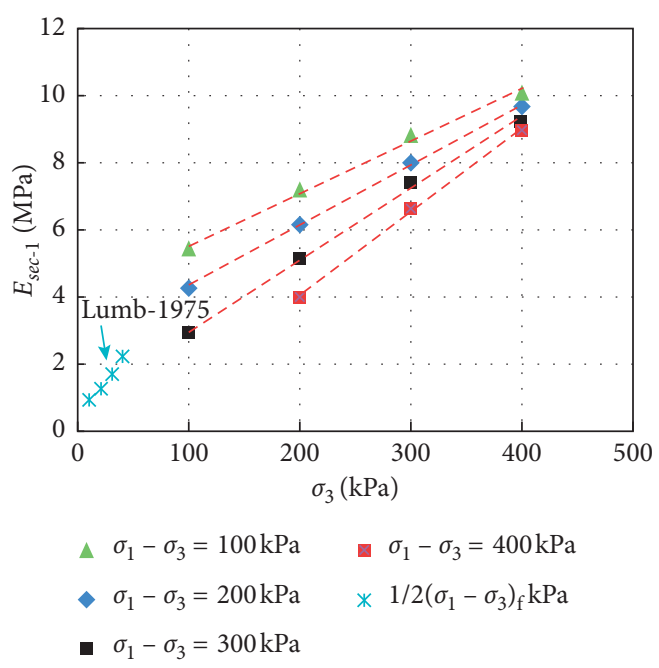

(a)

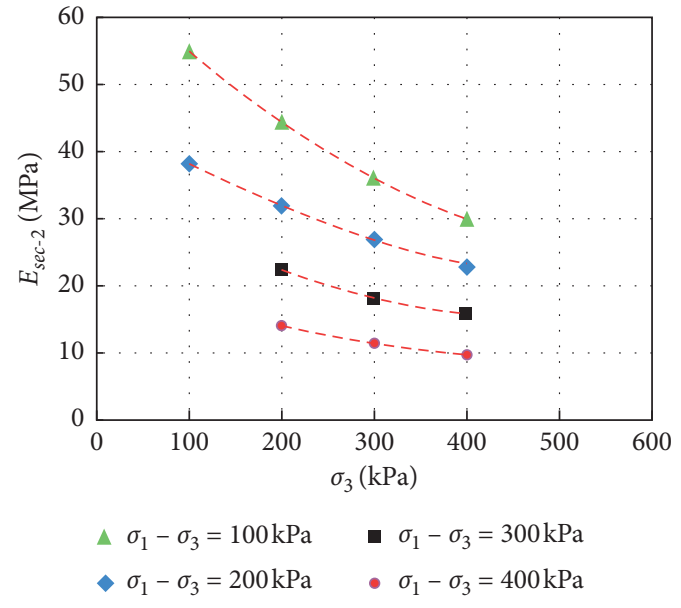

(b)

Figure 10: Correlation between secant modulus and confining pressure: (a) $E_{s e c-1}-\sigma_{3}$; (b) $E_{s e c-2}-\sigma_{3}$.

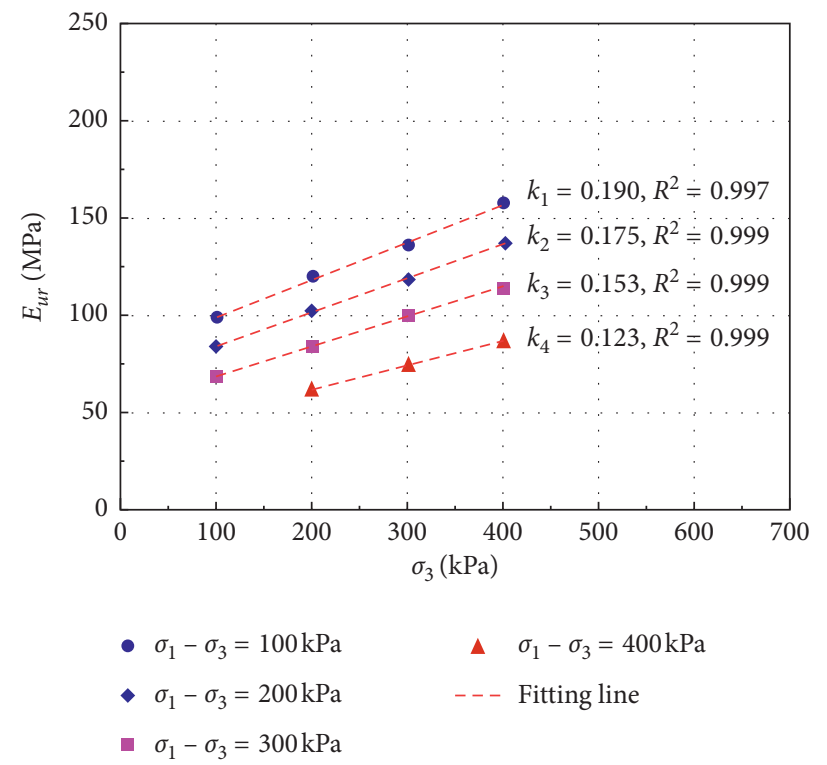

FIgURE 11: Correlation between deviator stress and unloading modulus.

The smaller the deviator stress applied in the path II stage, the larger the value of $E_{u r}$ obtained in the path III stage.

\section{Conclusions}

Triaxial tests and microscopic scanning experiment were conducted on intact CDG soil specimens in this study to investigate the mechanical behavior and microscopic pore distribution. Based on the test results, the following conclusions can be drawn:

(1) The stress-strain relationship reveals a shrinking behavior in the first-stage loading and a brittle behavior in the second-stage loading. In addition, the confining pressure was a benefit to the improvement of soil stiffness.
(2) The specimens under low confining pressure showed obvious localized failure characteristics. And the development of soil cracks was also affected by the principal stress direction, which caused the original pores and cracks to shrink or even partially close.

(3) The secant modulus $\left(E_{s e c-1}\right)$ in the first stage is positively correlated with the confining pressure, and it indicates that the confining pressure plays a role in restraining the lateral deformation of the soil, thus further strengthening the strength of the soil. Conversely, the secant modulus $\left(E_{s e c-2}\right)$ in the second stage decays exponentially with the confining pressure from $55.0 \mathrm{MPa}$ to $9.7 \mathrm{MPa}$.

(4) Unloading modulus $\left(E_{u r}\right)$ was affected by the confining pressure and the structural damage of the soil. 


\section{Data Availability}

The data used to support the findings of this study are included within the article

\section{Conflicts of Interest}

The authors declare that they have no conflicts of interest.

\section{Authors' Contributions}

Yanru Zhao wrote the original draft and contributed to derivation and data analysis. Tiande Wen reviewed and edited the article and conceptualized the study. Xiaohui Sun, Liping Huang, and Rui Chen reviewed and edited the article.

\section{Acknowledgments}

This research was funded by the National Natural Science Foundation of China (no. 51978413) and Shenzhen Science and Technology Program (no. KQTD2018041218 1337494).

\section{References}

[1] P. Lumb, "The residual soils of Hong Kong," Géotechnique, vol. 15, no. 2, pp. 180-194, 1965.

[2] J. S. Sharma, J. Chu, and J. Zhao, "Geological and geotechnical features of Singapore: an overview," Tunnelling and Underground Space Technology, vol. 14, no. 4, pp. 419-431, 1999.

[3] H. X. Lan, R. L. Hu, Z. Q. Yue, C. F. Lee, and S. J. Wang, "Engineering and geological characteristics of granite weathering profiles in South China," Journal of Asian Earth Sciences, vol. 21, no. 4, pp. 353-364, 2003.

[4] Z.-J. Zhang, C.-Q. Liu, Z.-Q. Zhao et al., "Behavior of redoxsensitive elements during weathering of granite in subtropical area using X-ray absorption fine structure spectroscopy," Journal of Asian Earth Sciences, vol. 105, pp. 418-429, 2015.

[5] C. F. Chiu and C. W. W. Ng, "Relationships between chemical weathering indices and physical and mechanical properties of decomposed granite," Engineering Geology, vol. 179, pp. 7689,2014

[6] D. G. Fredlund and H. Rahardjo, Soil Mechanics for Unsaturated Soils, John Wiley \& Sons, New York, NY, USA, 1993.

[7] C. W. W. Ng, W. T. Fung, C. Y. Cheuk, and L. Zhang, "Influence of stress ratio and stress path on behavior of loose decomposed granite," Journal of Geotechnical and Geoenvironmental Engineering, vol. 130, no. 1, pp. 36-44, 2004.

[8] H. El-Ramly, N. R. Morgenstern, and D. M. Cruden, "Probabilistic assessment of stability of a cut slope in residual soil," Géotechnique, vol. 55, no. 1, pp. 77-84, 2005.

[9] M. A. Hossain and J. H. Yin, "Shear strength and dilative characteristics of an unsaturated compacted completely decomposed granite soil," The Canadian Geotechnical Journal, vol. 47, pp. 112-1126, 2010.

[10] H. Rahardjo, O. B. Heng, and L. E. Choon, "Shear strength of a compacted residual soil from consolidated drained and constant water content triaxial tests," Canadian Geotechnical Journal, vol. 41, no. 3, pp. 421-436, 2004.

[11] B. X. Yuan, L. Xiong, L. Zhai et al., "Transparent synthetic soil and its application in modeling of soil-structure interaction using optical system," Frontiers in Earth Science, vol. 7276 pages, 2019.
[12] B. Yuan, M. Sun, L. Xiong, Q. Luo, S. P. Pradhan, and H. Li, "Investigation of 3D deformation of transparent soil around a laterally loaded pile based on a hydraulic gradient model test," Journal of Building Engineering, vol. 28, no. 3, Article ID 101024, 2020.

[13] B. X. Yuan, M. Sun, Y. X. Wang, L. H. Zhai, and Q. Z. Luo, "Full 3D displacement measuring system for 3D displacement field of soil around a laterally loaded pile in transparent soil," International Journal of Geomechanics, vol. 19, no. 5, Article ID 04019028, 2019.

[14] Y. Zhao, T. Wen, L. Shao et al., "Predicting hysteresis loops of the soil water characteristic curve from initial drying," Soil Science Society of America Journal, vol. 84, no. 5, pp. 1642$1649,2020$.

[15] Y. R. Zhao, H. Q. Yang, L. P. Huang, R. Chen, X. S. Chen, and S. Y. Liu, "Mechanical behavior of intact completely decomposed granite soils along multi-stage loading-unloading path," Engineering Geology, vol. 260, Article ID 105242, 2019.

[16] T. Wen, L. Shao, X. Guo, and Y. Zhao, "Experimental investigations of the soil water retention curve under multiple drying-wetting cycles," Acta Geotechnica, vol. 15, no. 11, pp. 3321-3326, 2020.

[17] J.-B. M. Dassekpo, X. Zha, and J. Zhan, "Compressive strength performance of geopolymer paste derived from completely decomposed granite (cdg) and partial fly ash replacement," Construction and Building Materials, vol. 138, pp. 195-203, 2017.

[18] S. Wang, D. Chan, and K. C. Lam, "Experimental study of the effect of fines content on dynamic compaction grouting in completely decomposed granite of Hong Kong," Construction and Building Materials, vol. 23, no. 3, pp. 1249-1264, 2009.

[19] A. W. Bishop and G. E. Blight, "Some aspects of effective stress in saturated and partly saturated soils," Géotechnique, vol. 13, no. 3, pp. 177-197, 1963.

[20] J. Zhao, Q. M. Gong, and Z. Eisensten, “Tunnelling through a frequently changing and mixed ground: a case history in Singapore," Tunnelling and Underground Space Technology, vol. 22, no. 38, 2007.

[21] J. M. Duncan and C. Y. Chang, "Nonlinear analysis of stress and strain in soils," Journal of the Soil Mechanics and Foundations Division, vol. 96, pp. 1629-1653, 1970.

[22] Y. Zhao, A. Noorbakhsh, M. Koopialipoor, A. Azizi, and M. M. Tahir, "A new methodology for optimization and prediction of rate of penetration during drilling operations," Engineering with Computers, vol. 36, pp. 1-9, 2019.

[23] T. Wen, L. Shao, X. Guo, Y. Zhao, L. Huang, and X. Chen, "Error correction of water evaporation loss on the unsaturated hydraulic conductivity," Soils and Foundations, vol. 59, no. 6, pp. 2341-2347, 2019.

[24] D. C. Lu, J. Y. Liang, X. L. Du, G. S. Wang, and T. Shire, “A novel transversely isotropic strength criterion for soils based on a mobilised plane approach," Géotechnique, vol. 69, no. 3, pp. 234-250, 2019.

[25] D. Lu, J. Liang, X. Du, C. Ma, and Z. Gao, "Fractional elastoplastic constitutive model for soils based on a novel 3D fractional plastic flow rule," Computers and Geotechnics, vol. 105, pp. 277-290, 2019.

[26] M. V. Galdos, L. F. Pires, H. V. Cooper, J. C. Calonego, C. A. Rosolem, and S. J. Mooney, "Assessing the long-term effects of zero-tillage on the macroporosity of Brazilian soils using X-ray Computed Tomography," Geoderma, vol. 337, pp. 1126-1135, 2019. 
[27] L. F. Pires, S. J. Mooney, A. C. Auler, B. Atkinson, and C. J. Sturrock, "X-ray microtomography to evaluate the efficacy of paraffin wax coating for soil bulk density evaluation," Geoderma, vol. 337, pp. 935-944, 2019.

[28] J. Perret, S. O. Prasher, A. Kantzas, K. Hamilton, and C. Langford, "Preferential solute flow in intact soil columns measured by SPECT scanning," Soil Science Society of America Journal, vol. 64, no. 2, pp. 469-477, 2000.

[29] T. C. Li, M. A. Shao, and Y. H. Jia, "Application of X-ray tomography to quantify macropore characteristics of loess soil under two perennial plants," European Journal of Soil Science, vol. 67, no. 3, pp. 266-275, 2016.

[30] X. Hu, Z.-C. Li, X.-Y. Li, and L.-y. Liu, "Quantification of soil macropores under alpine vegetation using computed tomography in the Qinghai Lake Watershed, NE Qinghai-Tibet Plateau," Geoderma, vol. 264, pp. 244-251, 2016.

[31] L. Luo, H. Lin, and S. Li, "Quantification of 3-D soil macropore networks in different soil types and land uses using computed tomography," Journal of Hydrology, vol. 393, no. 12, pp. 53-64, 2010.

[32] J. A. R. Borges, L. F. Pires, F. A. M. Cássaro et al., "X-ray microtomography analysis of representative elementary volume (REV) of soil morphological and geometrical properties," Soil and Tillage Research, vol. 182, pp. 112-122, 2018.

[33] J. Diel, H.-J. Vogel, and S. Schlüter, "Impact of wetting and drying cycles on soil structure dynamics," Geoderma, vol. 345, pp. 63-71, 2019.

[34] J. R. Helliwell, C. J. Sturrock, S. Mairhofer et al., "The emergent rhizosphere: imaging the development of the porous architecture at the root-soil interface," Scientific Report, vol. 7, Article ID 14875, 2017.

[35] Y. Feng, J. Wang, and T. Liu, "Using computed tomography images to characterize the effects of soil compaction resulting from large machinery on three-dimensional pore characteristics in an opencast coal mine dump," The Journal of Soils and Sediments, vol. 19, pp. 1-12, 2019.

[36] F. S. J. Martínez, M. A. Martín, and F. J. Caniego, "Multifractal analysis of discretized X-ray CT images for the characterization of soil macropore structures," Geoderma, vol. 156, no. 1-2, pp. 32-42, 2010.

[37] F. S. J. Martínez, F. J. Caniego, and C. García-Gutiérrez, "Lacunarity of soil macropore space arrangement of CT images: effect of soil management and depth," Geoderma, vol. 287 , pp. $80-89,2017$.

[38] A. L. Little, "The engineering classification of residual soils," in Proceedings of the Seventh International Conference on Soil Mechanics and Foundation Engineering, vol. 1, pp. 1-10, Mexico City, MX, USA, January 1969.

[39] ASTM D2487-06e1, Standard Practice for Classification of Soils for Engineering Purposes (Unified Soil Classification System), ASTM International, PO Box C700, West Conshohocken, PA 19428, USA, 2006.

[40] 2011 ASTM D7181-11, "Standard test method for consolidated drained triaxial compression test for soils".

[41] K. Terzaghi, "The shearing resistance of saturated soils and the angle between the planes of shear," Proceedings of the 1st International Conference on Soil Mechanics, vol. 1, pp. 54-56, 1936. 